Research Article

\title{
Seasonal Features and a Case Study of Tropopause Folds over the Tibetan Plateau
}

\author{
Jiali Luo $\mathbb{D}^{1},{ }^{1}$ Wenjun Liang, ${ }^{1}$ Pingping Xu, ${ }^{2}$ Haiyang Xue, ${ }^{1}$ Min Zhang, ${ }^{3}$ Lin Shang, \\ and Hongying Tian $\mathbb{1}^{1}$ \\ ${ }^{1}$ Key Laboratory for Semi-Arid Climate Change of the Ministry of Education, College of Atmospheric Sciences, \\ Lanzhou University, Lanzhou 730000, China \\ ${ }^{2}$ Xichang Satellite Launch Center, Xichang 615000, China \\ ${ }^{3}$ College of Ecology and Environment of Inner Mongolia University, Hohhot 010021, China \\ ${ }^{4}$ Shandong Provincial Climate Center, Jinan 250031, China \\ Correspondence should be addressed to Jiali Luo; luojl@lzu.edu.cn
}

Received 11 July 2019; Revised 22 September 2019; Accepted 14 October 2019; Published 25 November 2019

Academic Editor: Theodore Karacostas

Copyright ( 2019 Jiali Luo et al. This is an open access article distributed under the Creative Commons Attribution License, which permits unrestricted use, distribution, and reproduction in any medium, provided the original work is properly cited.

\begin{abstract}
Tropopause fold is the primary mechanism for stratosphere-troposphere exchange (STE) at the midlatitudes. Investigation of the features of tropopause folds over the Tibetan Plateau (TP) is important since the TP is a hotspot in global STE. In this study, we investigated seasonal features of the tropopause fold events over the TP using the 40-year ERA-Interim reanalysis data. The development of a tropopause folding case is specifically examined. The results show that shallow tropopause folds occur mostly in spring, while medium and deep folds occur mostly in winter. The multiyear mean monthly frequency of shallow tropopause folds over the TP reaches its maximum value of about 7\% in May and then decreases gradually to its minimum value of $1 \%$ in August and increases again since September. Deep folds rarely occur in summer and autumn. Both the seasonal cycle and seasonal distribution of total tropopause folds over the TP are dominated by shallow folds. The relative high-frequency areas of medium and deep folds are located over the southern edge of the TP. The westerly jet movement controls the displacement of the highfrequency folding region over the TP. The region of high-frequency tropopause folds is located in the southern portion of the plateau in spring and moves northward in summer. The jet migrates back to the south in autumn and is located along about $30^{\circ} \mathrm{N}$ in winter, and the region where folds occur most frequently also shifts southward correspondingly. A medium fold event that occurred on 29 December 2018 is used to demonstrate the evolution of a tropopause fold case over the TP in winter; that is, the folding structure moves from west to east, the tropopause pressure is greater than $320 \mathrm{hPa}$ over the folding region, while it is about $200 \mathrm{hPa}$ in the surrounding areas, and the stratospheric air with high potential vorticity (PV) is transported from the high latitudes to the plateau by meridional winds. A trajectory model result verifies the transport pathway of the air parcels during the intrusion event.
\end{abstract}

\section{Introduction}

Tropopause fold events, which may lead to stratospheric intrusion, are mainly caused by the upper tropospheric frontal development and jet stream [1-3]. As a mesoscale process, the tropopause fold forms in response to strong descent at the tropopause level and usually decays after 1 2 days [4]. The stratospheric air within the trough of the tropopause fold usually mixes irreversibly into the troposphere [5] and subsequently affects the radiative process, thermal structure, and atmospheric composition in the troposphere [6-9]. Therefore, tropopause folds are recognized as the primary mechanism for stratosphere-troposphere exchange (STE) at the midlatitudes [6].

The tropopause fold associated with the polar front jet may intrude deeply into the troposphere, while the other major type of tropopause folds that is associated with the subtropical jet stream and subtropical front can rarely extend downward below $500 \mathrm{hPa}$ [4]. Previous studies pointed out that the tropopause fold events mostly occur in the 
midlatitude region [10]. Lin et al. [11] found that stratospheric intrusions play a major role in spring-time high- $\mathrm{O}_{3}$ events over the high-altitude western US. Their effect on exchange of large amounts of air is of great concern; that is, even a strong tropospheric $\mathrm{O}_{3}$ enhancement in Hawaii can be caused by direct transport of midlatitude stratospheric $\mathrm{O}_{3}$ [12].

The Tibetan Plateau (TP) is known as "the third pole" on the earth, which plays an important role in global weather and climate [13-15]. It is situated at $25-40^{\circ} \mathrm{N}, 70-105^{\circ} \mathrm{E}$, where the subtropical jet stream moves northward from winter to summer. The complex terrain and the unique dynamical and thermal features of the TP make it a key pathway of global STE [16-18]. The STE associated with the tropopause fold events accounts for a large proportion of total STE over the TP [19-21]. It may impact regional climate by altering the content of tropospheric greenhouse gases such as $\mathrm{O}_{3}$ and water vapor. Yin et al. [22] found that surface $\mathrm{O}_{3}$ in the Nam Co Station (in the southern-central region of the Tibetan Plateau) is affected by stratospheric intrusions.

Since tropopause folds can transport ozone-rich and high potential vorticity (PV) air into lower levels and subsequently affect the tropospheric environment and mesoscale weather $[3,11,12,21,23-28]$, the knowledge on the frequency and distribution of tropopause fold events is important for understanding climatological STE and extratropical synoptic-scale-to-mesoscale weather systems. Sprenger et al. [29] used a 2 pvu (potential vorticity unit) isosurface to investigate 1-year climatology of global tropopause folds and found that folds occur preferentially in the subtropics and shallow folds occur most frequently. Chen et al. [19] found that the stratospheric intrusions occur mostly in winter over the TP and the location varies with the movement of the westerly jet, but the results are based on a single-year analysis. Most of the studies focusing on tropopause fold events based on numerical simulations show that the stratosphere-to-troposphere transport (STT) associated with tropopause folds over the TP plays an important role in the local STE process $[21,30]$.

Although STE processes over the TP, especially the STE caused by the tropopause fold events, are widely discussed in recent years, most results are based on case studies $[20,21,31]$, while only a few studies investigate the climatology of spatial distribution and the seasonal variation of the tropopause fold events over the TP, e.g., [29, 32]. To fully understand the above issue is of significant implications for further investigation of STE over the TP.

In this study, statistical analysis and case studies are combined to analyze the characteristics of tropopause fold events over the TP. Section 2 briefly describes the data and analysis method. The statistical analysis focusing on seasonal distribution and variation of tropopause fold events is discussed in Section 3. The case study of the evolution of a tropopause fold event is shown in Section 4. Summaries and conclusions are presented in Section 5.

\section{Data and Methods}

2.1. ERA-Interim. The ERA-Interim reanalysis is from the European Centre for Medium-Range Weather Forecasts
(ECMWF) [33]. In this study, we use 6-hourly data over 40 years from 1 January 1979 to 31 December 2018 to calculate seasonal mean variables in spring (March, April, and May), summer (June, July, and August), autumn (September, October, and November), and winter (December, January, and February). PV, wind field, temperature at 37 pressure levels, and pressure at 2 pvu isosurface are used in this study. The horizontal resolution of the dataset is 1 degree $\times 1$ degree (latitude $\times$ longitude).

\subsection{Tropopause Definition and Identification of Tropopause} Folds. The tropopause separates the troposphere from the stratosphere. Note that it is not a fixed boundary. Multiple tropopauses are found based on the thermal tropopause defined by the World Meteorological Organization (WMO) in the extratropics [34-39]. Dynamical tropopause can be regarded as a continuous quasimaterial surface [40] and is widely used in STE studies. The dynamical tropopause is typically determined by the absolute PV value within $1-4$ pvu [41, 42], and we define the 2 pvu isosurface as the tropopause in this study.

Vertical profiles of $\mathrm{O}_{3}$, water vapor, and PV are used to define the tropopause fold $[5,43,44]$. The maxima of PV and Q-vector divergence are also regarded as good criteria to identify tropopause fold events $[45,46]$ in previous model output or reanalysis whose resolutions are coarse. However, diabatically generated low-level PV and PV anomalies produced by friction near high orography can potentially merge with stratospheric PV. Sprenger et al. [29] proposed a new method named "3D labelling" to identify tropopause folds. This method has been applied in previous studies [32, 47, 48]. The algorithm is easily applicable to reanalysis datasets and offers the possibility to distinguish between shallow and deep folds compared to the approach of Elbern et al. [29, 46]. In the present study, we implement the "3D labelling" method based on Škerlak et al. [48] to separate troposphere from stratosphere. The algorithm is summarized as follows: Figure 1.

(1) The 2 pvu isosurface is chosen to be the tropopause.

(2) The first 2 pvu isosurface from the top downward is marked as "1" in Figure 1.

(3) If the specific humidity on the second 2 pvu surface from the top downward is lower than $0.1 \mathrm{~g} \cdot \mathrm{kg}^{-1}$, the 2 pvu isosurface is marked as "2" in Figure 1.

(4) " 3 " in Figure 1 is the third 2 pvu surface from the top downward.

(5) $\Delta p$ is the vertical distance between "1" and "2," i.e., the vertical distance between the first and the second 2 pvu isosurface.

A tropopause fold event is identified if " 1 ," "2," and " 3 " all exist at the same time. In this method, the value of the vertical distance $\Delta p$ between the upper tropopause and the middle tropopause crossing of the dynamical tropopause is used to identify and clarify folds [29]. Folds with $50 \leq \Delta p<200 \mathrm{hPa}$ are classified as shallow folds, and those with $200 \leq \Delta p<350 \mathrm{hPa}$ are classified as medium folds, while folds with $\Delta p \geq 350 \mathrm{hPa}$ are defined to be deep folds. 


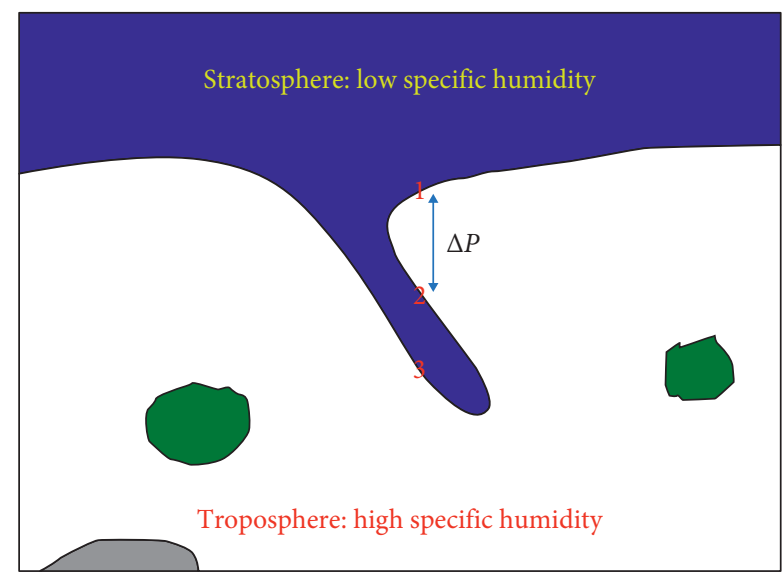

FIgURE 1: Schematic vertical cross section of the identification of tropopause folds. Stratospheric cutoff or diabatically produced cyclonic PV anomalies are shown by green areas. The gray region is the surface-bond cyclonic PV anomaly. Tropopause folds are defined as multiple crossings of the dynamical tropopause in a vertical profile. $\Delta p$ is used to classify the fold.

The criterion " 3 " is used to divide the relatively high-PV structure into a stratospheric part (with relatively low specific humidity) and a stratospheric cutoff or diabatically produced cyclonic PV anomaly (with relatively high specific humidity).

2.3. Model Descriptions. We use the hybrid single-particle Lagrangian integrated trajectory (HYSPLIT) model to track backward trajectories in this study. The HYSPLIT model assumes a three-dimensional particle distribution [32]. The mean particle trajectory is the integration of the particle position vector in space and time [48]. It has been widely used in studies of airmass transport during tropopause folds $[41,49]$.

A 48-hour simulation from 00:00 UTC 29 Dec 2018 to 00:00 UTC 31 Dec 2018 was also performed to compare the evolution of a tropopause fold case diagnosed from reanalysis data. The model we use is the Weather Research and Forecasting (WRF) model (V3.9.1). In this study, the simulation resolution is $45 \mathrm{~km} \times 45 \mathrm{~km}$ and has 29 levels from the ground to $50 \mathrm{hPa}$. The simulation schemes include the Grell 3D cumulus convection scheme, the RRTM longwave radiation scheme, the Goddard shortwave radiation scheme, the Lin microphysics scheme, the MYJ boundary layer scheme, and the NLSM surface scheme. The simulation was driven by the initial conditions and boundary conditions from data with 1 degree $\times 1$ degree horizontal resolution.

\section{Seasonal Variation and Distribution}

We first investigate seasonal mean frequencies of shallow, medium, and deep tropopause folds over the TP $\left(25-40^{\circ} \mathrm{N}\right.$, $70-105^{\circ} \mathrm{E}$ ) during $1979-2018$ (Figure 2). The seasonal mean frequency $F_{1}$ is defined as follows:

$$
F_{1}=\frac{D_{1}}{D_{\mathrm{t}}},
$$

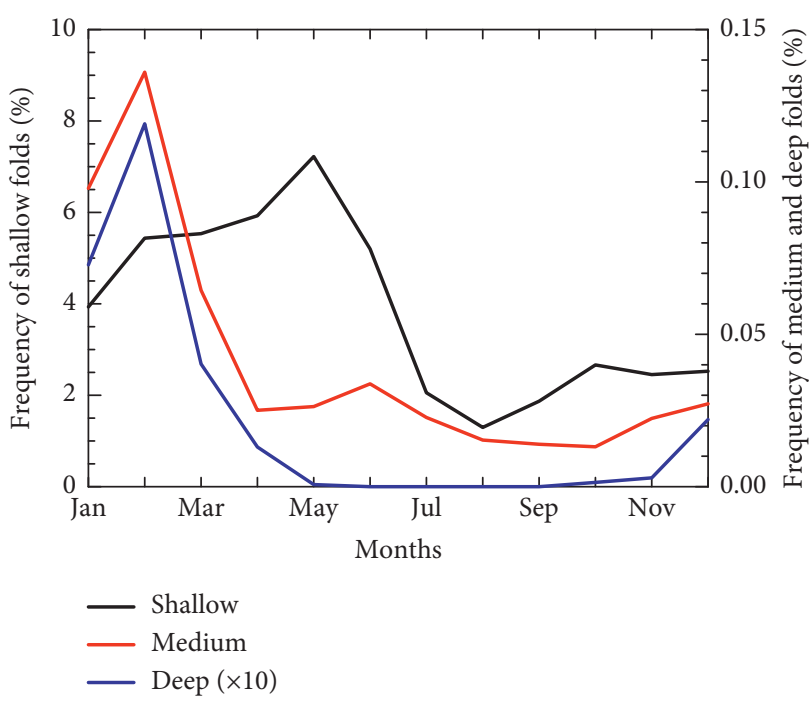

FIGURE 2: Seasonal cycles of regionally averaged frequencies (\%) of shallow (black line), medium (red line), and deep (blue line) tropopause folds over the TP $\left(25-40^{\circ} \mathrm{N}, 70-105^{\circ} \mathrm{E}\right)$ during $1979-$ 2018. The values for deep folds have been multiplied by a factor 10 .

where $D_{1}$ is the regional mean occurrence of a specific type of fold for a month and $D_{t}$ is the total occurrence of this specific type of fold over the TP during the study period. The results show that shallow folds play a major role in the TP's regional mean tropopause fold events in all seasons. It is clear that medium folds and deep folds over the TP demonstrate similar seasonality, while the seasonality of shallow folds is quite different. Specifically, shallow folds peak in spring, while both medium and deep folds most often occur in winter. A significant maximum occurrence frequency of shallow folds is found in May with the value exceeding 7\%, while the frequencies in July-December are all below 3\%. The frequency of shallow folds declines sharply from May to July and reaches the minimum value of $1.2 \%$ in August and then increases from September to December. Generally, the frequencies during the first half-year are higher than those during the second half-year. The maximum frequencies of medium (about $0.14 \%$ ) and deep (about $0.012 \%$ ) folds both occur in February. The frequencies of medium and deep folds both drop in spring, but the frequency of medium folds fluctuates between $0.01 \%$ and $0.05 \%$ after March and deep folds rarely occur during the period.

We further analyzed seasonal spatial distributions of the three types of tropopause fold events. Figure 3 shows the 40year (1979-2018) mean seasonal averages of shallow tropopause fold frequencies for spring, summer, autumn, and winter. Since we use daily data in this study, the frequency $F_{2}$ is defined as follows:

$$
F_{2}=\frac{D_{2}}{D_{s}}
$$

where $D_{2}$ represents the number of days when the shallow tropopause fold occurred at a specific location and $D_{\mathrm{s}}$ is the number of days during the whole season in this specific location. 


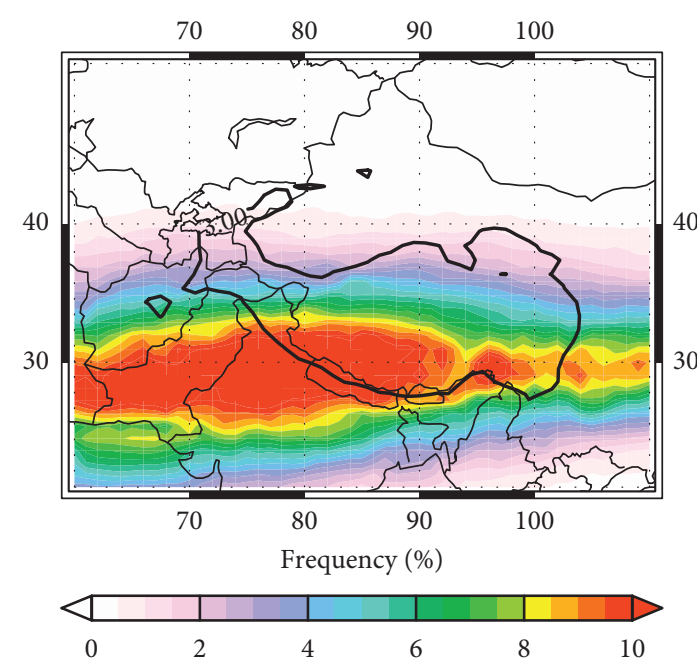

(a)

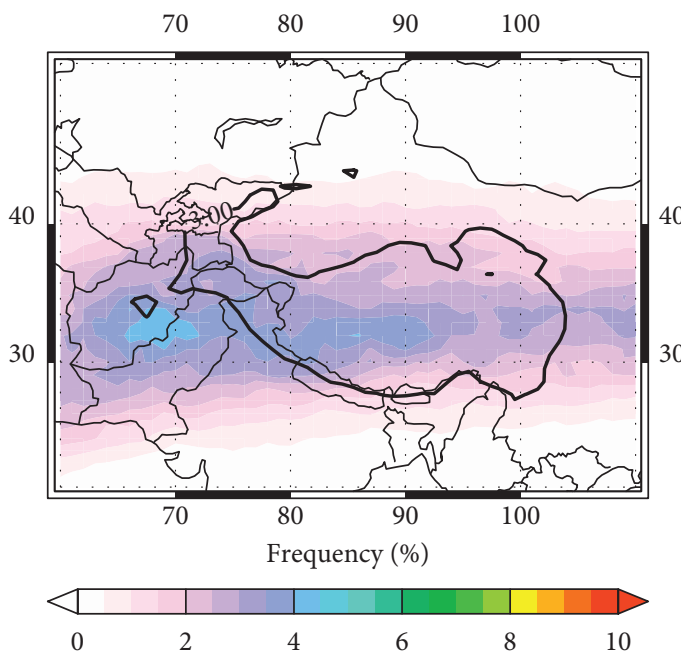

(c)

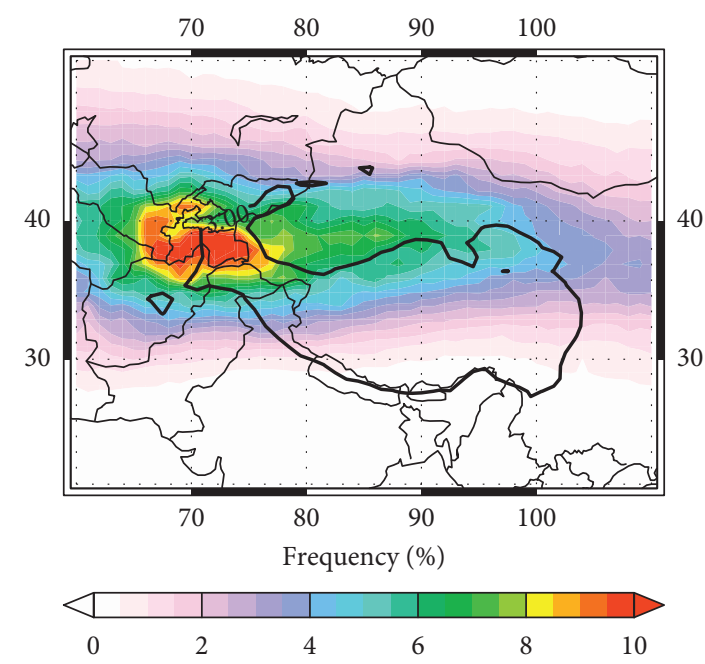

(b)

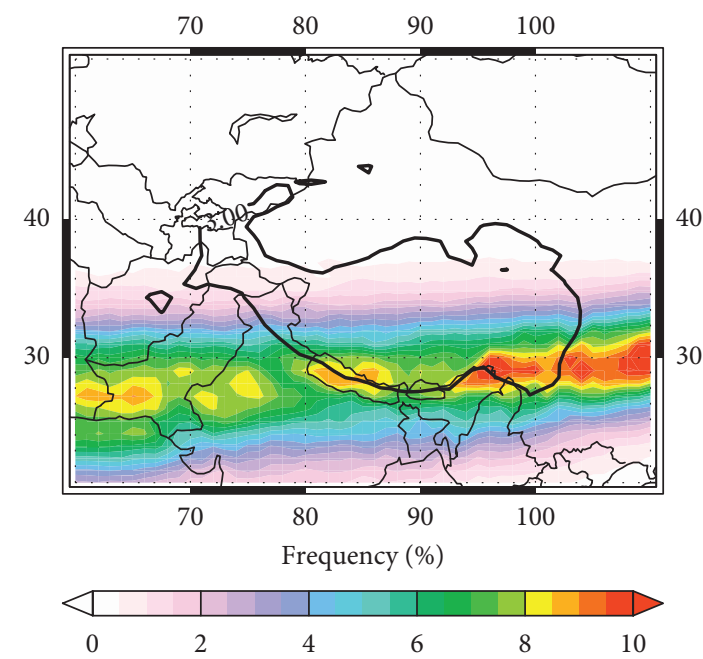

(d)

Figure 3: Seasonal averages of shallow tropopause fold frequencies (\%) for spring (March, April, and May (MAM)) (a), summer (June, July, and August (JJA)) (b), autumn (September, October, and November (SON)) (c), and winter (December, January, and February (DJF)) (d) during 1979-2018. The location of the Tibetan Plateau (3 km elevation) is also shown in the maps (black contours).

Shallow tropopause fold frequencies present a zonal distribution pattern in all the four seasons, while the southnorth migration of the high-frequency center from winter to summer is evident. It is shown that shallow tropopause fold events occur mostly in the southern part of the TP in spring, and the highest frequency is about $10 \%$ around the southwestern TP. The area where the frequency is higher than $10 \%$ accounts for almost half of the TP in spring. The high-frequency region shifts to the north of the plateau in summer. Although the highest frequency exceeds $10 \%$ over the northwestern TP in summer, fewer folds occur over the plateau in summer than in spring. In autumn, the region of shallow tropopause fold events migrates southward. Folds often occur in the central TP but rarely occur to the south of $30^{\circ} \mathrm{N}$. The frequencies are less than $5 \%$. The high-frequency region moves further south and is located in the southern TP again in winter, while the occurrence frequency of shallow folds also increases.
Although medium and deep folds only account for a small part of total folds in the northern hemisphere [32, 47, 48], previous studies have shown that deep stratospheric intrusions are an important reason for the occurrence of high-surface $\mathrm{O}_{3}$ events over the TP. The identification of the spatial distributions of all the types of tropopause events over the TP will have great implications for the study of high-surface $\mathrm{O}_{3}$ events. As shown in Figure 2, medium and deep folds peak in winter, and both occur most frequently over the southern edge of the plateau (Figures 4 and 5). While medium folds can still occur in other three seasons except over the plateau and to the west of the plateau, deep folds can only be found in spring and winter along the southern edge of the TP. Previous studies have revealed that deep tropopause folds are associated with midlatitude baroclinic waves $[49,50]$ and thus are most frequent in winters in respective hemispheres [48]. The results from Figures 3-5 agree well with those of the previous 


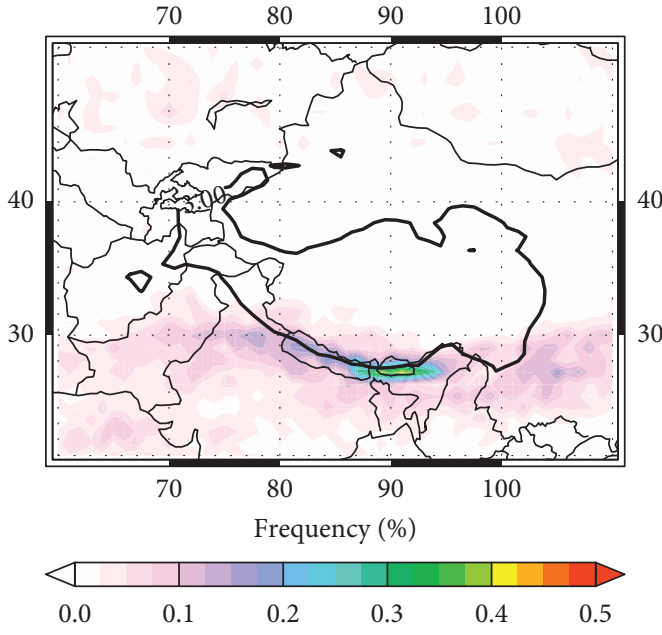

(a)

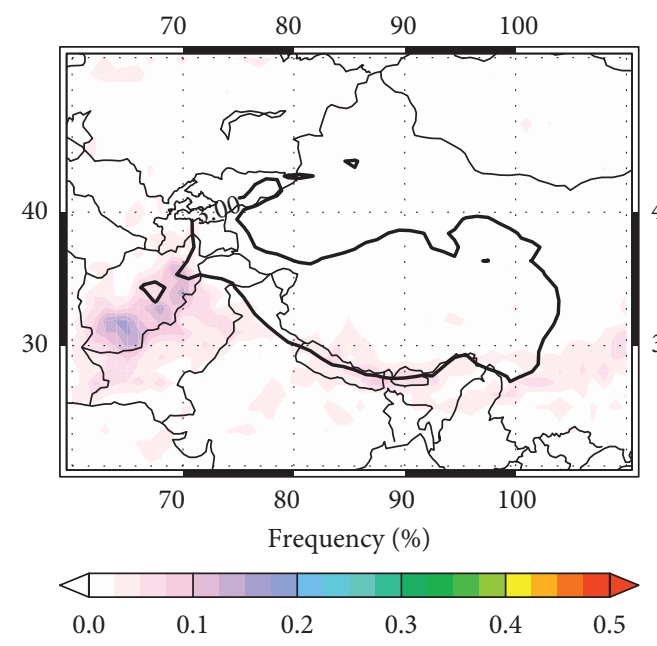

(c)

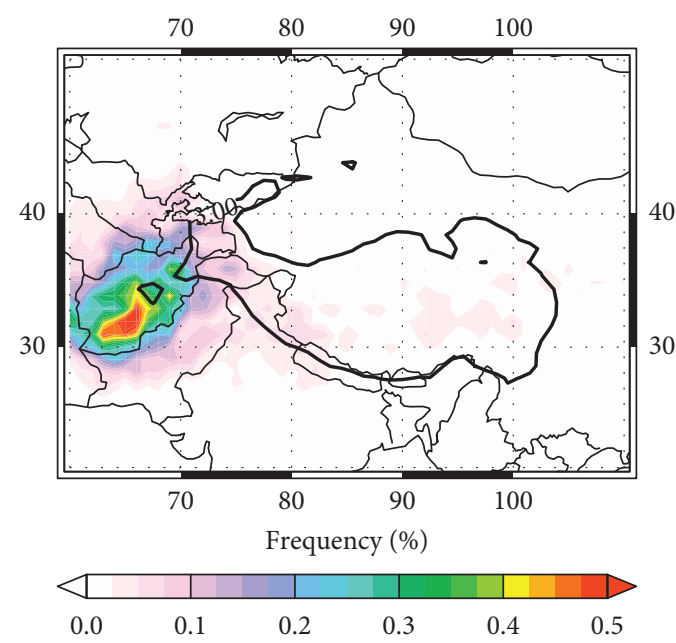

(b)

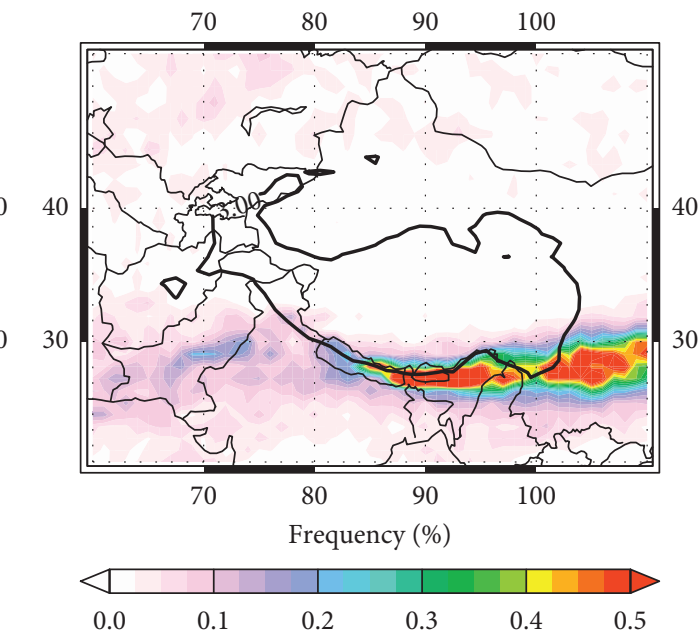

(d)

Figure 4: The same as Figure 3, but for medium tropopause fold frequencies.

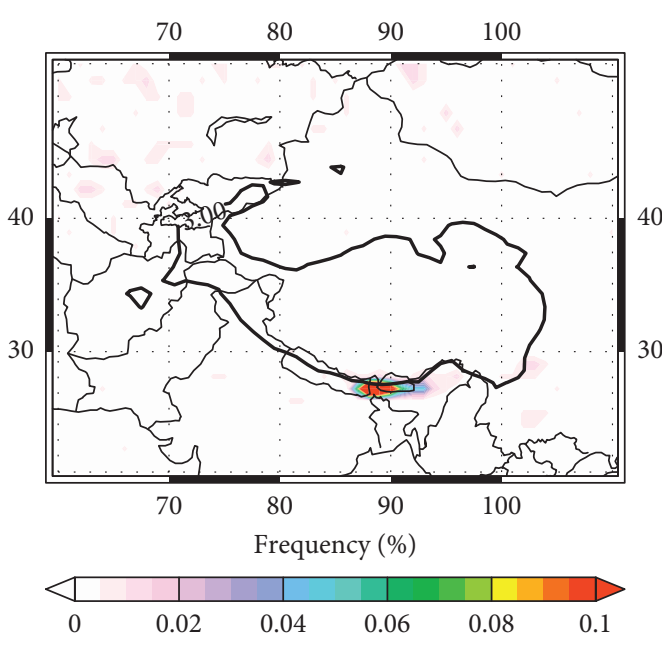

(a)

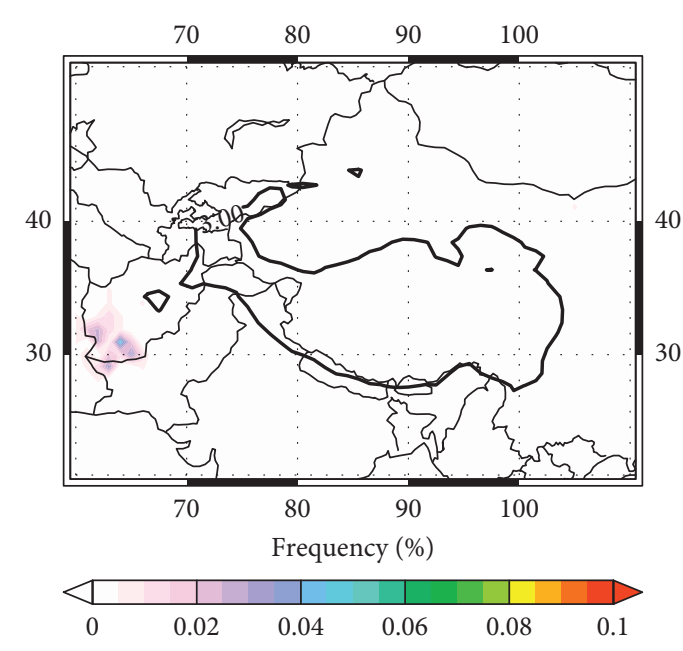

(b)

Figure 5: Continued. 


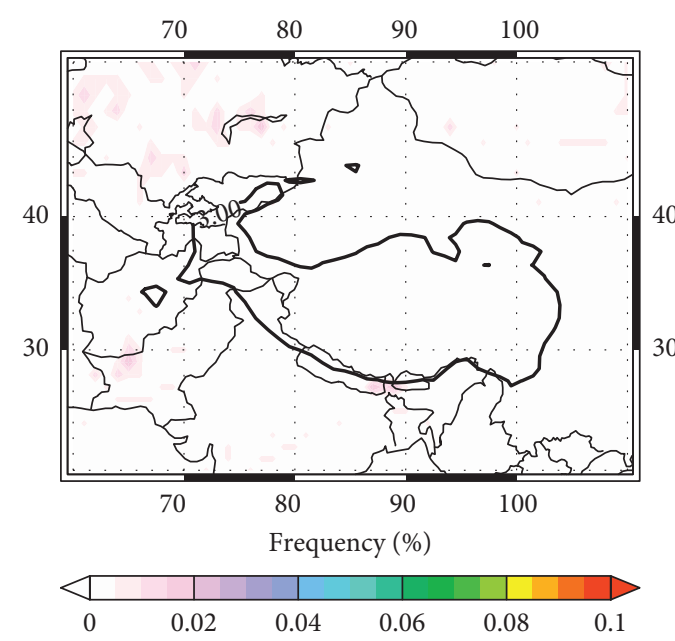

(c)

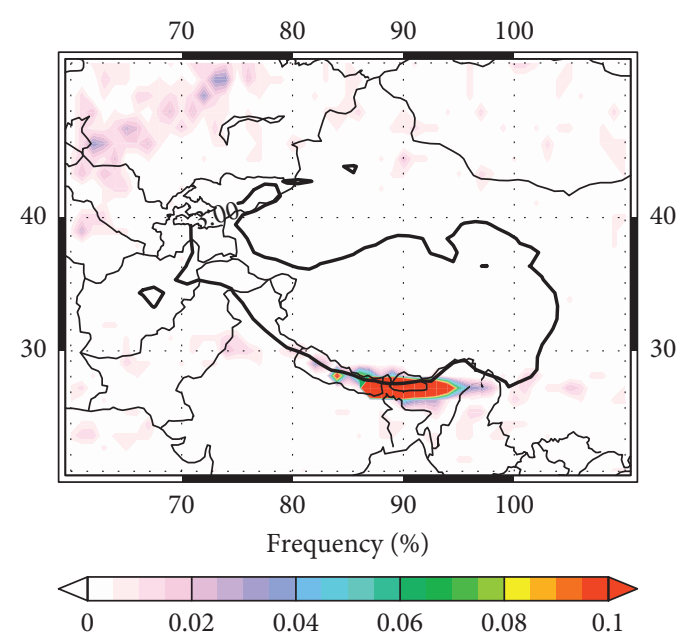

(d)

Figure 5: The same as Figure 3, but for deep tropopause fold frequencies.

studies of Tyrlis et al. [47] and also complement their findings, which do not show the occurrences of all the three types of folds in winter half-year.

Since shallow folds account for a majority of total tropopause fold events over the TP, the seasonal frequency and seasonal spatial distribution of total folds are almost the same as those of shallow folds (figures not shown). The south-north migration of the relatively high-frequency area is a significant feature of total tropopause folds over the TP.

Several studies have revealed that the tropopause fold event is clearly linked to the location of the jet stream over the TP $[20,51,52]$. As we mentioned above, the relatively high-frequency regions of both shallow tropopause folds and total folds demonstrate a seasonal south-north movement (Figure 3). Figure 6 shows that this meridional migration of the region where high folds occur frequently is consistent with the migration of the westerly jet in the upper levels. We define the maximum wind speed of the westerly jet as the westerly jet core and investigate its variation. The 40 -year mean jet core in spring is along $28^{\circ} \mathrm{N}$, and it moves to the north of the plateau at around $42^{\circ} \mathrm{N}$ in summer. When the westerly jet moves to the north of the TP and becomes weaker in summer, the tropopause folds rarely occur above the TP (also see reference [20]). In autumn, the jet core is located along about $36^{\circ} \mathrm{N}$ and becomes stronger. The strongest westerly jet is situated to the south of the plateau in winter, when tropopause folds occur frequently below it. Deep STTs that are associated with stratospheric intrusions also occur most frequently in winter [20, 21, 52]. Additionally, the extent of the westerly stream (green dashed contours in Figure 6) in summer is the smallest. Both the extension and the location of the westerly jet affect the occurrence of tropopause fold events.

Seasonal averages of the westerly jet and total fold frequency are displayed in Figure 7. The total tropopause fold frequency is the sum of the frequency of shallow, medium, and deep folds. Consistent with the seasonal spatial distribution of tropopause fold occurrence, the jet stream also shows a northward movement from winter to summer. At the same time, the jet belt becomes narrow and the wind speed decreases. Areas of folding event occurrence are mostly consistent with the regions of high average wind speed in spring and winter. Although the westerly jet is the weakest in summer, tropopause fold events occur more frequently in summer than in autumn, which is probably attributed to the fact that the TP is a heating source in summer that affects atmospheric stability. One more significant feature is that tropopause folds mostly occur in the entrance of the westerly jet, where the isentropic gradient is large in all seasons.

\section{Case Studies}

Section 3 indicates that shallow tropopause folds dominate the seasonal cycle, seasonal distribution, and frequencies of total tropopause folds over the TP. It also reveals that the frequency of shallow tropopause folds peaks in May above the plateau, while medium and deep folds mostly occur in winter. In this section, we select a medium tropopause fold case that occurred in December 2018 to show the evolution of the fold. The selection of the case is based on the $3 \mathrm{D}$ labelling method.

As we use a 2 pvu isosurface to represent the dynamical tropopause surface, the pressure of 2 pvu is analyzed to illustrate the variation of the tropopause height during the study period (Figure 8). The tropopause was lower (high tropopause pressure corresponds to low tropopause height) over the TP and to the northeast of the TP than that over the surrounding areas on the day we chose. The relatively low tropopause extended from the high-latitude region to the southern TP. The evolution of this tropopause fold event over a 12-hour period is shown in Figure 8. At 12:00 UTC 29 December 2018, the tropopause pressure was about $300 \mathrm{hPa}$ at around $30^{\circ} \mathrm{N}, 97^{\circ} \mathrm{E}$ and higher than $240 \mathrm{hPa}$ over the western TP. The relatively low tropopause region extended and moved eastward at 18:00 UTC. The pressure of the 

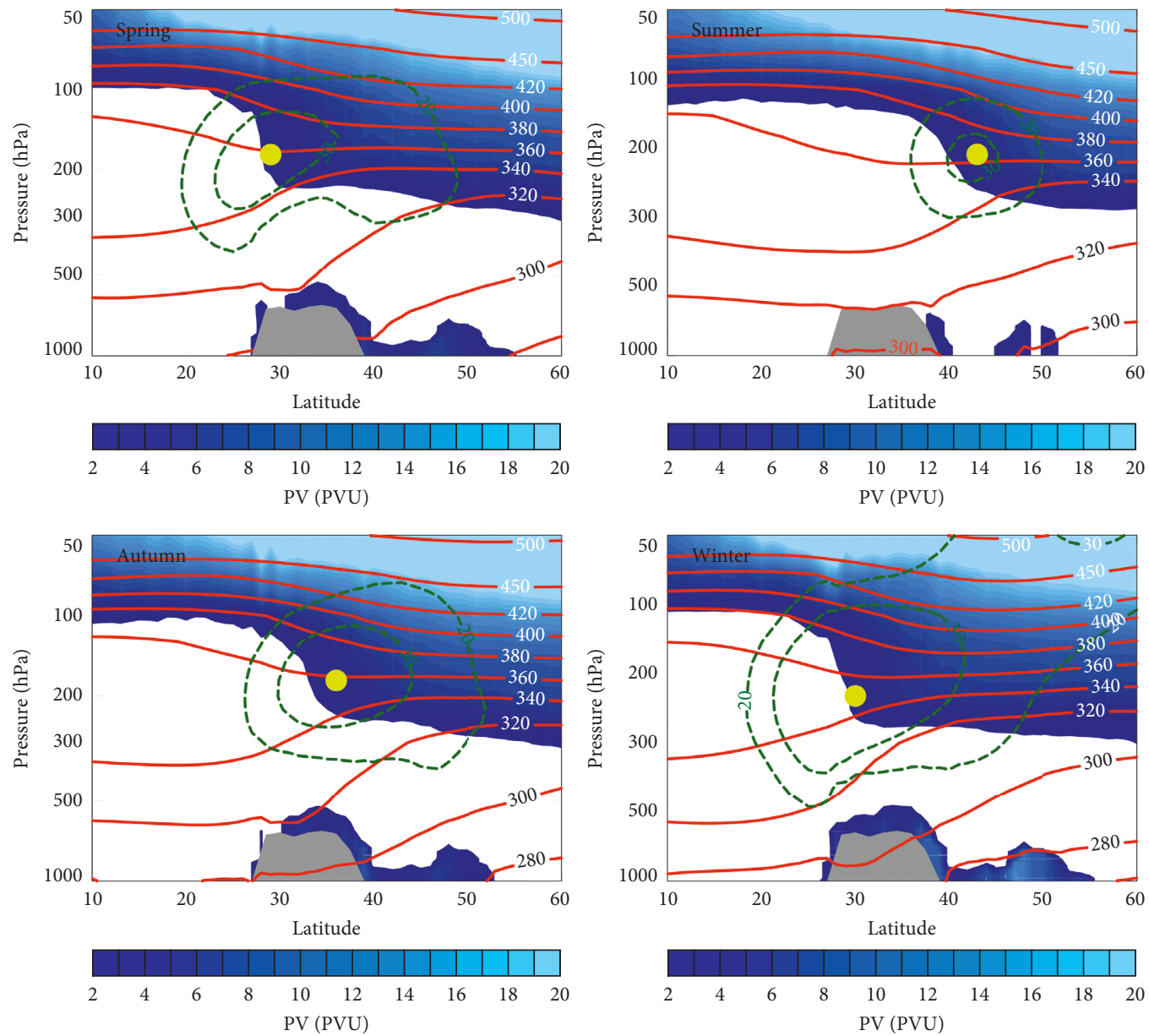

(a)

Figure 6: Pressure-latitude cross sections of seasonal average PV (color shadings; pvu), potential temperature (red lines; K), and zonal winds (green dashed lines; $\mathrm{m} / \mathrm{s}$ ) along $90^{\circ} \mathrm{E}$ during $1979-2018$. The yellow dots represent the jet core. The area shaded in gray denotes the TP terrain.

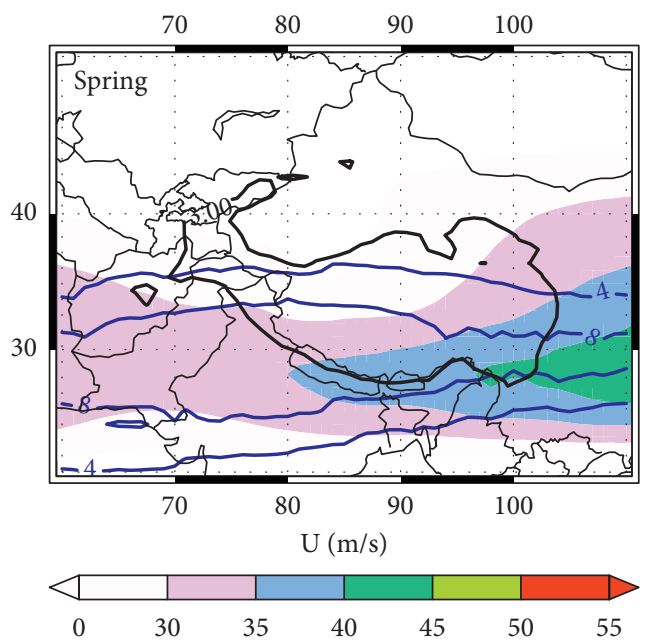

(a)

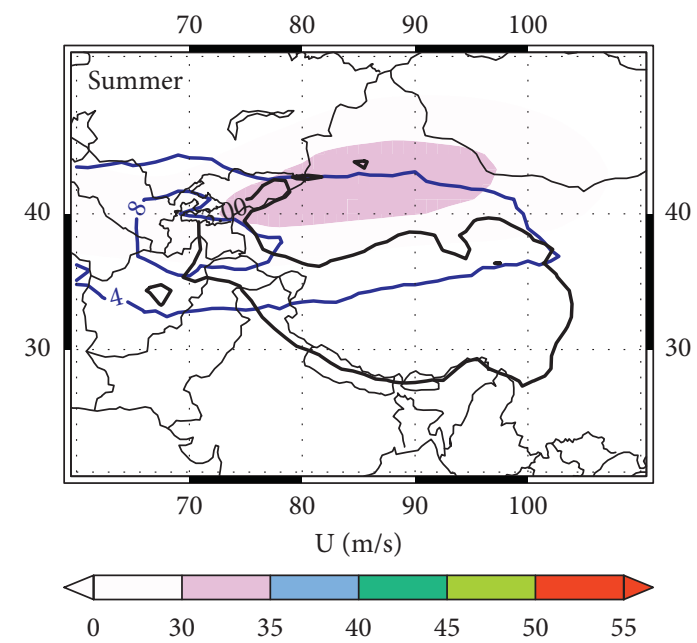

(b)

Figure 7: Continued. 


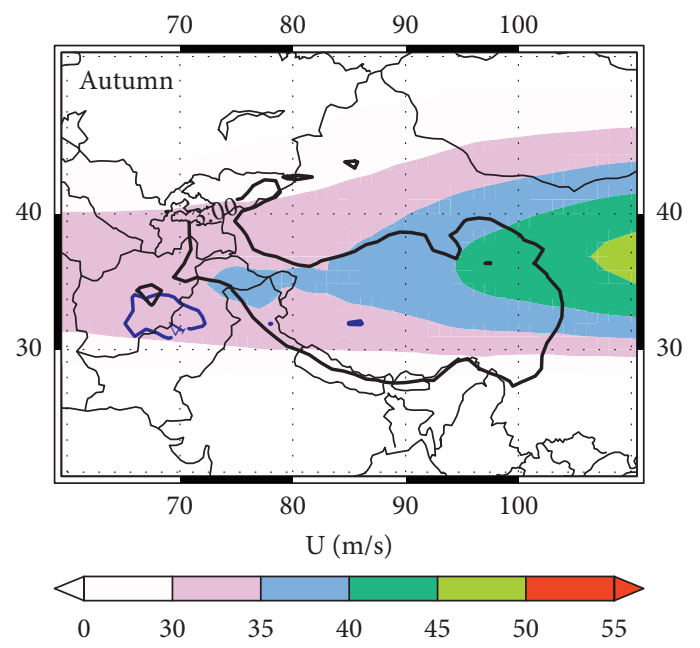

(c)

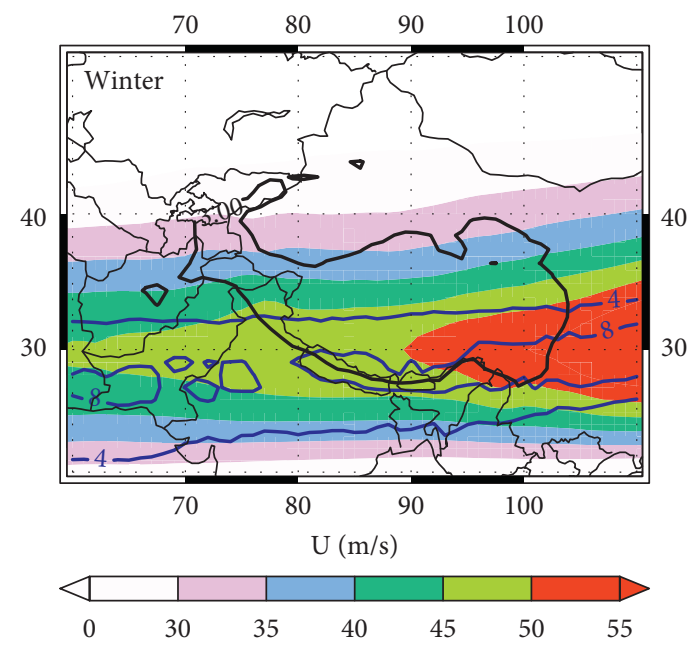

(d)

FIgURE 7: Seasonal mean U wind (color shadings) at $200 \mathrm{hPa}$ during $1979-2018$. The blue contours represent $4 \%$ and $8 \%$ total tropopause fold frequencies. Black contours indicate the location of the TP.

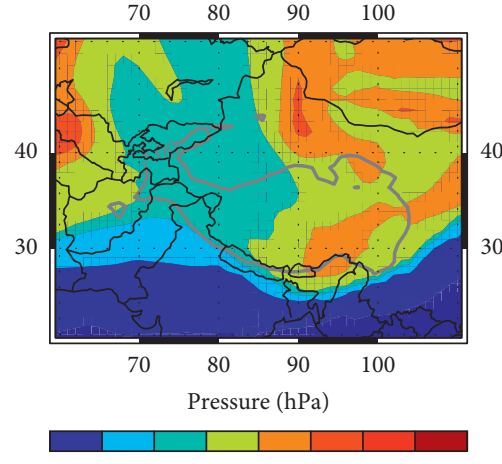

$150 \quad 200 \quad 240 \quad 280 \quad 320 \quad 360 \quad 400$

(a)

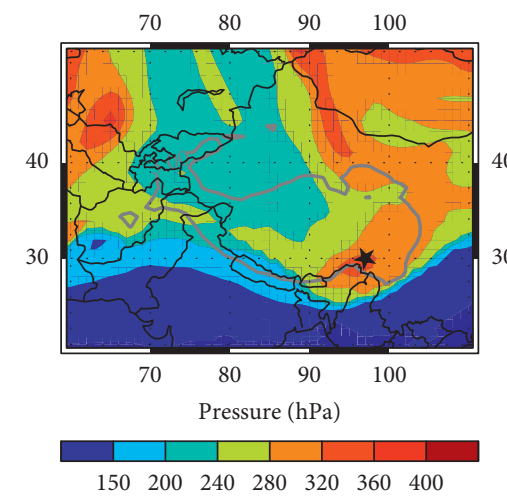

(b)

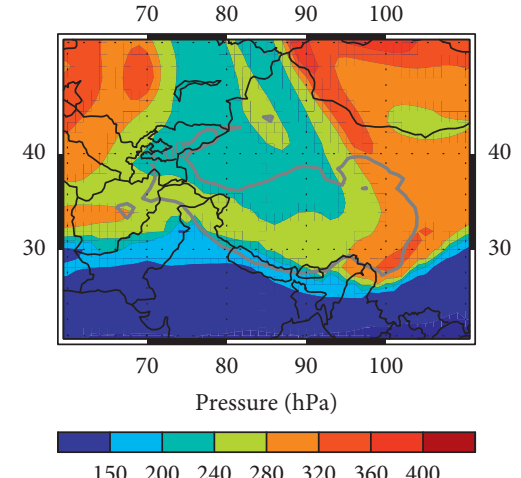

(c)

FIGURE 8: Pressure on the 2 pvu tropopause surface (color shadings; hPa) at 12:00 UTC 29 December 2018 (a), $18: 00$ UTC 29 December 2018 (b), and 00:00 UTC 30 December 2018 (c). Gray contours indicate the location of the TP ( $3 \mathrm{~km}$ elevation). The black pentagram indicates the departure point of the trajectory shown in Figure 12.

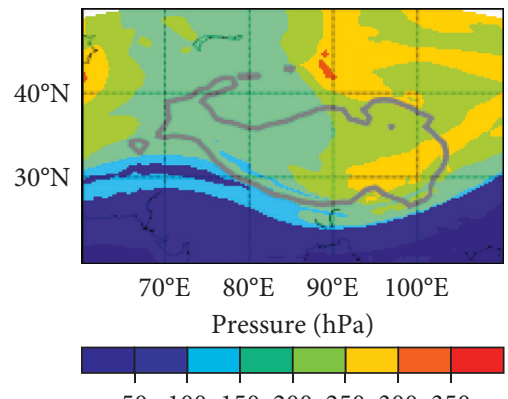

$50 \quad 100150200250300350$

(a)

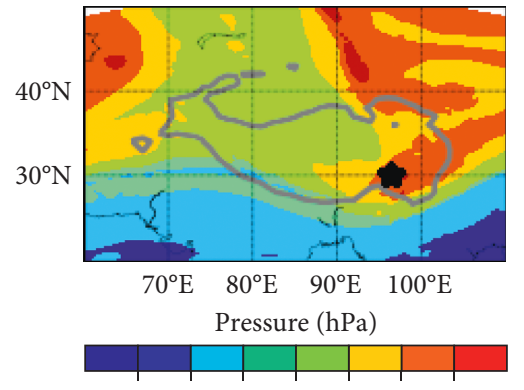

50100150200250300350

(b)

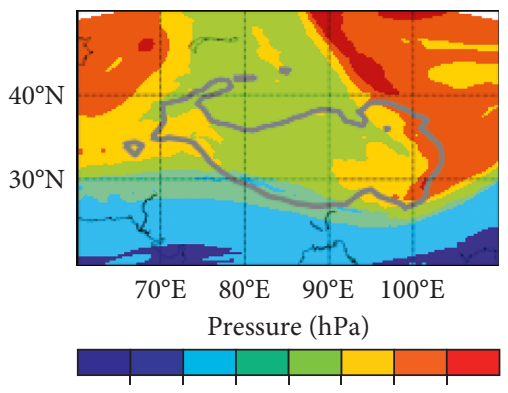

50100150200250300350

(c)

FIgURE 9: The same as Figure 8, but for the WRF output.

lowest tropopause was about $350 \mathrm{hPa}$ at about $30^{\circ} \mathrm{N}, 97^{\circ} \mathrm{E}$. We have pointed out that medium tropopause folds mostly occurred at the southern edge of the TP. The relatively low tropopause region moved further eastward at 00:00 UTC, while the region where the tropopause pressure was lower than $320 \mathrm{hPa}$ almost moved out of the plateau. In this folding 


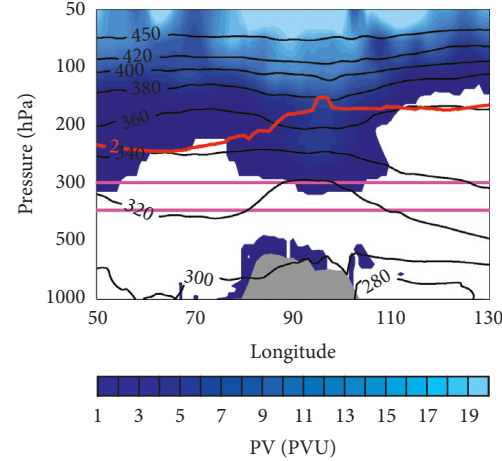

(a)

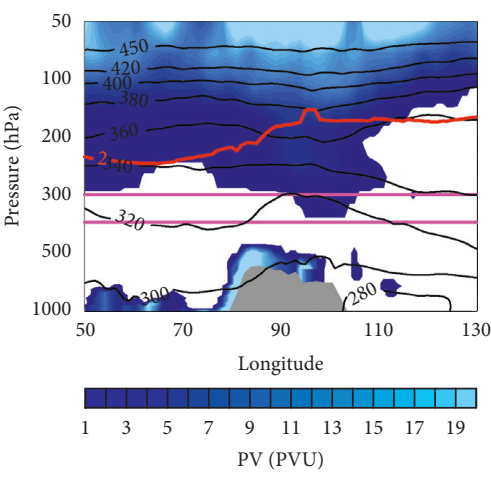

(b)

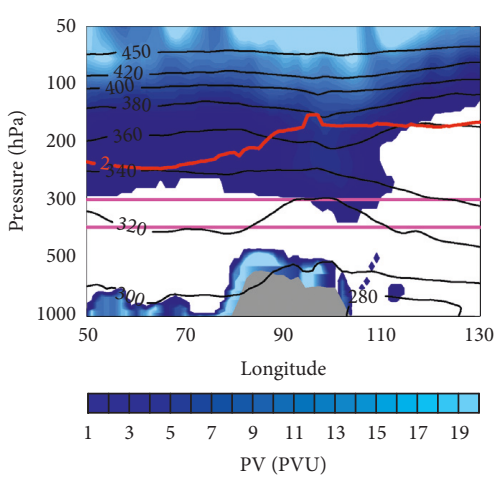

(c)

FIgURE 10: Pressure-longitude cross section of PV (color shadings; pvu) and potential temperature (black lines; K) at $30^{\circ} \mathrm{N}$ at $12: 00 \mathrm{UTC} 29$ December 2018 (a), 18:00 UTC 29 December 2018 (b), and 00:00 UTC 30 December 2018 (c). The red lines denote the mean 2 pvu contour at $30^{\circ} \mathrm{N}$ in December between 1979 and 2018. Pink lines represent $300 \mathrm{hPa}$ and $400 \mathrm{hPa}$ surfaces. The area shaded in gray indicates the TP terrain.
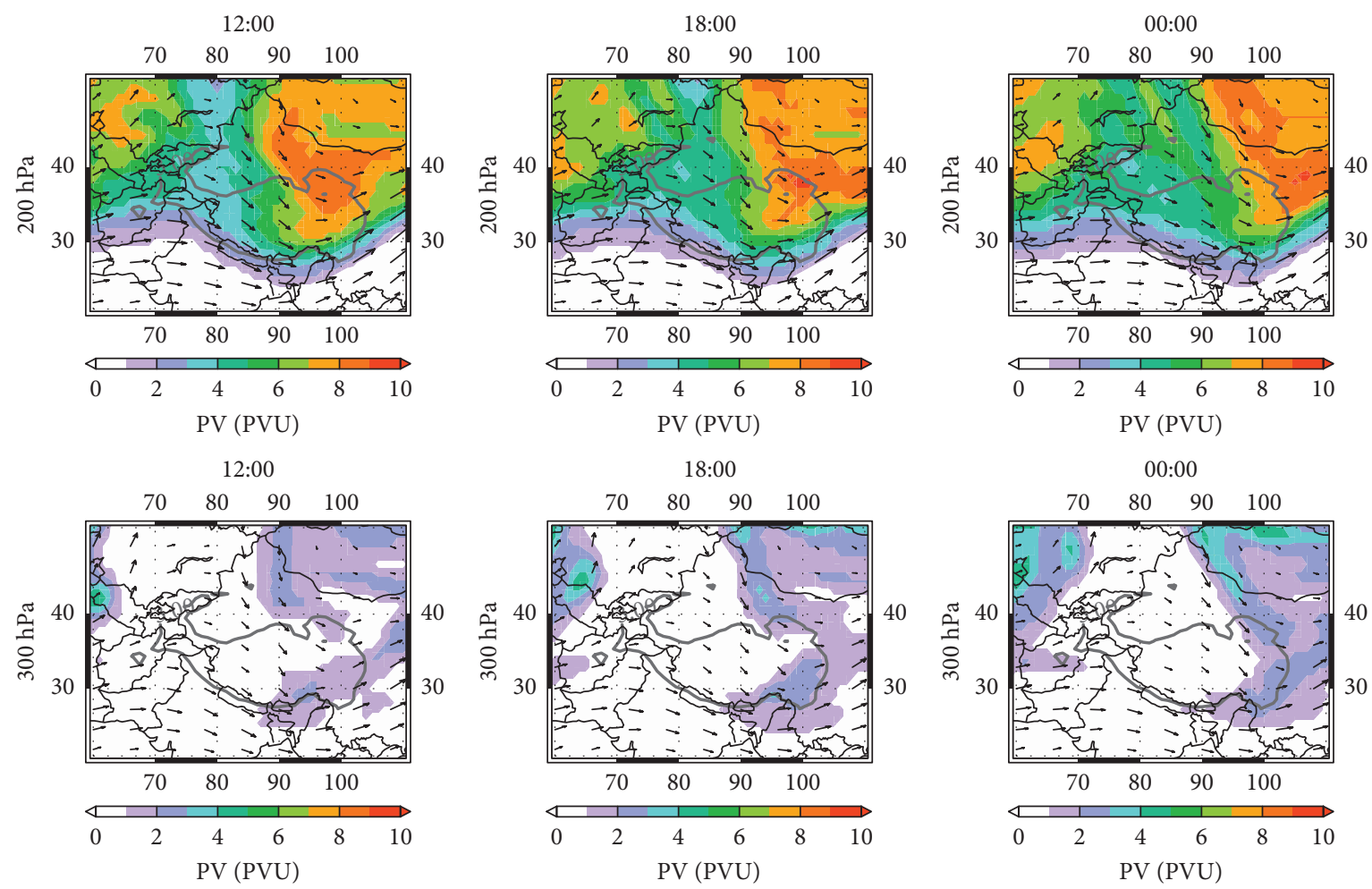

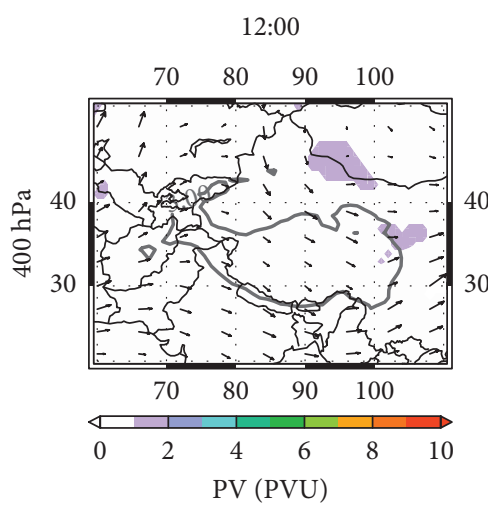

(a)

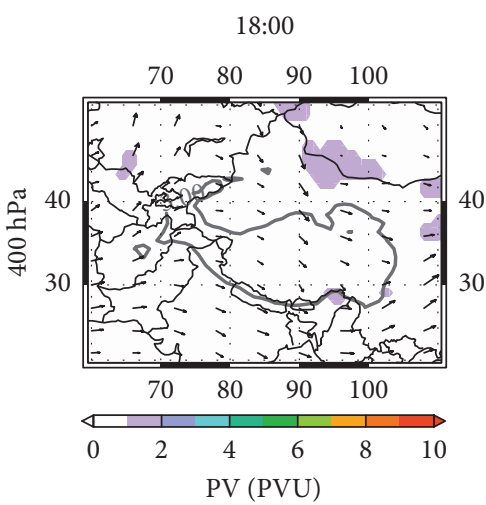

(b)

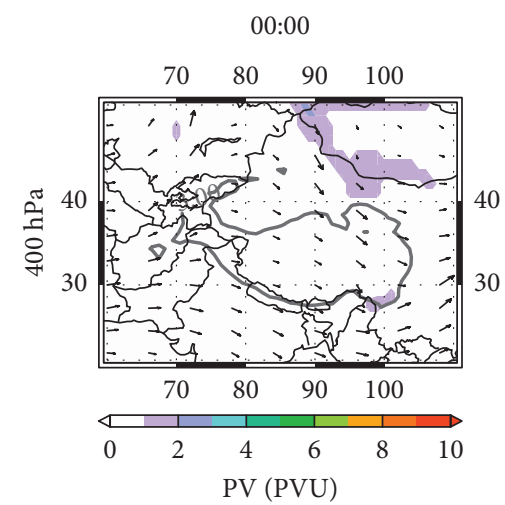

(c)

Figure 11: PV (color shadings; pvu) and wind field (vectors; m/s) at $200 \mathrm{hPa}$ (upper), $300 \mathrm{hPa}$ (middle), and $400 \mathrm{hPa}$ (lower) at 12:00 UTC 29 December 2018 (a), 18:00 UTC 29 December 2018 (b), and 00:00 UTC 30 December 2018 (c). Gray contours indicate the location of the TP (3 km elevation). 
case, the stratospheric intrusion came from the north of the plateau, and the folding event moved across the TP from the central area to the southeast. The folding region extended both horizontally and vertically during the period. A similar structure and the folding evolution features are also shown in the high spatial resolution WRF simulation results (Figure 9) which indicate that the fold events can be resolved in a regional model.

Figure 8 shows that the tropopause pressure is between $360 \mathrm{hPa}$ and $200 \mathrm{hPa}$ in this case. PV and wind field at $200 \mathrm{hPa}, 300 \mathrm{hPa}$, and $400 \mathrm{hPa}$ are then chosen to analyze both the horizontal and vertical ranges of this tropopause fold event (Figure 11). The air over the TP at $200 \mathrm{hPa}$ was mainly from stratosphere (air with a PV value greater than 2 pvu is labelled as stratospheric air) during the entire period, and the stratospheric intrusion gradually became stronger while it extended eastward. Similar to the results shown in Figure 8, the region controlled by relatively high $\mathrm{PV}$ values moved from the northwest of the TP to the southeast in response to wind fields. The movement was also clear at $300 \mathrm{hPa}$ and coincided with pressure variation at $2 \mathrm{pvu}$ isosurface. The stratospheric intrusion was evident in the southern edge of the plateau at 12: 00 UTC and moved southeastward since then. The area of relatively high PV extended at 18:00 UTC, and the PV value increased later. The stratospheric high-PV air which was transported from high latitude to troposphere above the plateau is associated with southern downward meridional wind during the period. At $400 \mathrm{hPa}$, no stratospheric air was found in the plateau region except for the southeastern TP. We have concluded that medium and deep folds only exist over the southern TP in winter in Section 3.

To visualize the stratospheric intrusion that is associated with the tropopause fold event, we analyze the vertical cross sections of PV along $30^{\circ} \mathrm{N}$ (Figure 10), and the 40 -year mean dynamical tropopause pressure in December is superimposed upon the cross sections. Figure 10 shows that the tropopause height was lower than the mean tropopause height in December during the study period. An evident folding structure existed over the plateau. The tropopause fold developed from west to east, and the tropopause reached about $400 \mathrm{hPa}$ at 18:00 UTC and 00:00 UTC between $90^{\circ} \mathrm{E}$ and $110^{\circ} \mathrm{E}$. Consistent with data in Figures 8, 9, and 11, the tropopause fold moved from the west of the plateau to the east of it.

The diagnostic analysis above reveals the properties of the evolution of this tropopause fold event. 12-hour backward trajectories are used to verify the intrusion feature (Figure 12). We release three air parcels at $30^{\circ} \mathrm{N}, 97^{\circ} \mathrm{E}$ at different heights and obtain trajectories at $2 \mathrm{~km}, 2.5 \mathrm{~km}$, and $3 \mathrm{~km}$ levels above the ground. It is evident that the downward transport began at about 15:00 UTC 29 December 2018. The pressure of the downward movement was about $150 \mathrm{hPa}$. The air parcel at $30^{\circ} \mathrm{N}, 97^{\circ} \mathrm{E}$ at $2 \mathrm{~km}$ height was from the northwest, which is consistent with the wind field shown in Figure 11. Trajectories of all the three parcels show almost the same horizontal transport pathway, indicating that the relatively high-PV parcels at this location had the same source. A northwest-southeast stratospheric intrusion led to the STT event.

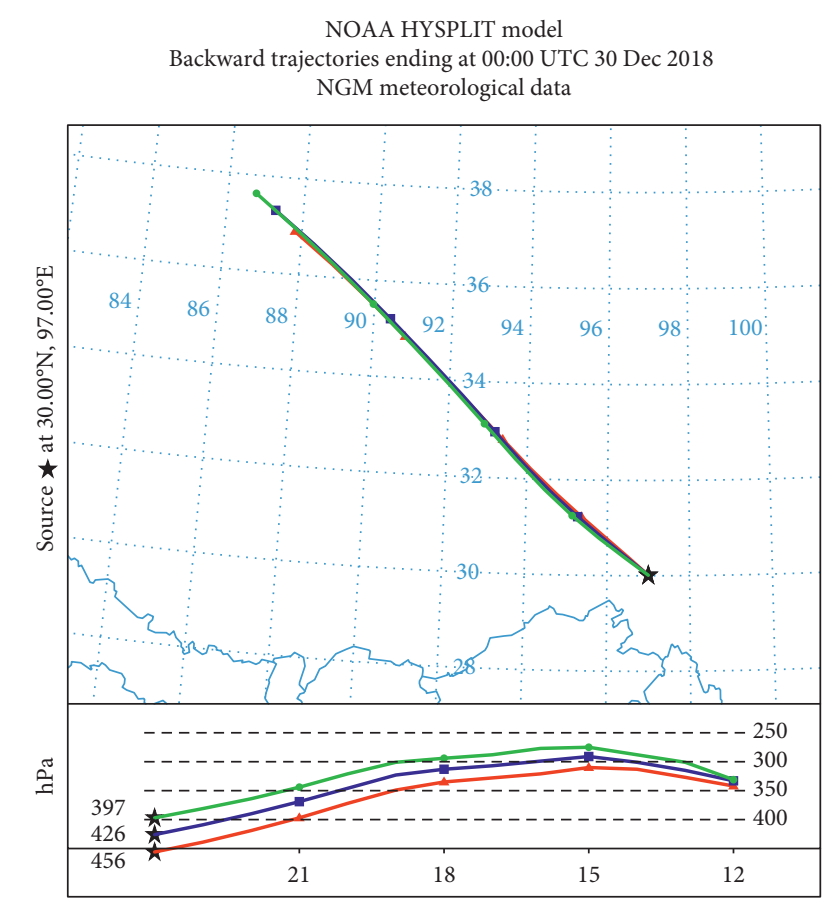

Figure 12: Backward trajectories at $2 \mathrm{~km}(456 \mathrm{hPa}), 2.5 \mathrm{~km}$ $(426 \mathrm{hPa})$, and $3 \mathrm{~km}(397 \mathrm{hPa})$ levels above the ground. The top part of the panel shows the time evolution of trajectories in the horizontal region, and the bottom part of the panel shows the vertical variation of trajectories with time. 00:00 UTC 30 December 2018 is chosen as the beginning time, and the trajectories are 12 hours before this time. The departure point is located at $30^{\circ} \mathrm{N}, 97^{\circ} \mathrm{E}$.

\section{Conclusions}

Using ERA-Interim 6-hourly data, we have studied the characteristics of tropopause fold events over the TP based on the 3D labelling method. We focus on the climatology of seasonal variation and distribution of tropopause folds over the TP. The development of a tropopause fold event is specifically investigated in the present study based on reanalysis data and results of a trajectory model.

Our analysis shows that shallow tropopause folds mostly occur in May with the frequency of 7\%, while medium and deep folds usually occur in winter. The frequency of shallow folds decreases from May to August (minimum, 1.2\%) and increases from September to subsequent May. Shallow tropopause folds play an important role in the plateau and account for a majority of total fold occurrence over the TP. Both the seasonal cycle and the seasonal distribution of total folds over the TP are mainly dominated by shallow folds. The westerly jet movement controls the south-north displacement of the high-frequency shallow fold region over the plateau. The region of the highest frequency of tropopause folds is located in the southwestern plateau in spring and moves northward in summer. The jet migrates back to the south in autumn and winter, and the region of fold occurrence moves correspondingly. The high-frequency areas for medium and deep folds are found at the southern edge of the TP. The deep folds rarely occur in summer and autumn.

A medium tropopause fold event that occurred on 29 December 2018 is specifically studied to demonstrate the 
evolution of a tropopause fold case over the TP in winter. The tropopause pressure could be larger than $360 \mathrm{hPa}$ and even reached about $400 \mathrm{hPa}$ in the southern edge of the TP, whereas it was only about $200 \mathrm{hPa}$ in the surrounding areas. Stratospheric air with high PV from high latitude was associated with the southward meridional winds into troposphere over the plateau. Results of the WRF simulation and the trajectory model have verified the evolution of the folding event and transport pathway of upper-level air parcels during the period of this case.

Overall, our analysis has revealed the seasonal features of tropopause fold events over the TP. A specific case study is performed to demonstrate the evolution of a medium tropopause fold event. However, this study is based on the ERA-Interim reanalysis data, whose resolution is relatively coarse to reveal the details of tropopause fold events. In the future, we will use multiple datasets such as aircraft and LIDAR measurements combined with chemical tracers to optimize the detection of tropopause folds and further investigate their characteristics.

\section{Data Availability}

The ERA-Interim data used to support the findings of this study are available at https://apps.ecmwf.int/datasets/data/ interim-full-daily/levtype $=\mathrm{sfc} /$.

\section{Conflicts of Interest}

The authors declare no conflicts of interest.

\section{Acknowledgments}

This research was sponsored by the Strategic Priority Research Program of the Chinese Academy of Sciences under Grant no. XDA17010106, the National Natural Science Foundation of China under Grant no. 41705021, and the Research Launch Fund for High-Level Talents in Inner Mongolia University under Grant no. 21800-5195121.

\section{References}

[1] C. Appenzeller and H. C. Davies, "Structure of stratospheric intrusions into the troposphere," Nature, vol. 358, no. 6387, pp. 570-572, 1992.

[2] B. J. Hoskins and F. P. Bretherton, "Atmospheric frontogenesis models: mathematical formulation and solution," Journal of the Atmospheric Sciences, vol. 29, no. 1, pp. 11-37, 1972.

[3] A. O. Langford, "Stratosphere-troposphere exchange at the subtropical jet: contribution to the tropospheric ozone budget at midlatitudes," Geophysical Research Letters, vol. 26, no. 16, pp. 2449-2452, 1999.

[4] K. Mohanakumar, Stratosphere Troposphere Interactions, Springer, Berlin, Germany, 2008.

[5] E. F. Danielsen, "Stratospheric-tropospheric exchange based on radioactivity, ozone and potential vorticity," Journal of the Atmospheric Sciences, vol. 25, no. 3, pp. 502-518, 1968.

[6] A. Stohl, P. Bonasoni, P. Cristofanelli et al., "Stratospheretroposphere exchange: a review, and what we have learned from STACCATO," Journal of Geophysical Research, vol. 108, no. D12, p. 8516, 2003.
[7] C. Ordóñez, D. Brunner, J. Staehelin et al., "Strong influence of lowermost stratospheric ozone on lower tropospheric background ozone changes over Europe," Geophysical Research Letters, vol. 34, no. 7, Article ID L07805, 2007.

[8] A. S. Lefohn, H. Wernli, D. Shadwick, S. J. Oltmans, and M. Shapiro, "Quantifying the importance of stratospherictropospheric transport on surface ozone concentrations at high- and low-elevation monitoring sites in the United States," Atmospheric Environment, vol. 62, pp. 646-656, 2012.

[9] D. Akritidis, E. Katragkou, P. Zanis et al., "A deep stratosphere-to-troposphere ozone transport event over Europe simulated in CAMS global and regional forecast systems: analysis and evaluation," Atmospheric Chemistry and Physics, vol. 18, no. 20, pp. 15515-15534, 2018.

[10] J. F. Austin and R. P. Midgley, "The climatology of the jet stream and stratospheric intrusions of ozone over Japan," Atmospheric Environment, vol. 28, no. 1, pp. 39-52, 1994.

[11] M. Lin, A. M. Fiore, L. W. Horowitz et al., "Transport of Asian ozone pollution into surface air over the western United States in spring," Journal of Geophysical Research: Atmospheres, vol. 117, no. D21, 2012.

[12] O. R. Cooper, A. Stohl, G. Hübler et al., "Direct transport of midlatitude stratospheric ozone into the lower troposphere and marine boundary layer of the tropical Pacific Ocean," Journal of Geophysical Research, vol. 110, no. D23, p. D23310, 2005.

[13] J. E. Kutzbach, P. J. Guetter, W. F. Ruddiman, and W. L. Prell, "Sensitivity of climate to late cenozoic uplift in Southern Asia and the American west: numerical experiments," Journal of Geophysical Research, vol. 94, no. D15, pp. 18393-18407, 1989.

[14] J. E. Kutzbach, W. L. Prell, and W. F. Ruddiman, "Sensitivity of eurasian climate to surface uplift of the Tibetan plateau," The Journal of Geology, vol. 101, no. 2, pp. 177-190, 1993.

[15] A. M. Duan and G. X. Wu, "Role of the Tibetan Plateau thermal forcing in the summer climate patterns over subtropical Asia," Climate Dynamics, vol. 24, no. 7-8, pp. 793-807, 2005.

[16] J. Steinwagner, M. Milz, T. von Clarmann et al., "HDO measurements with MIPAS," Atmospheric Chemistry and Physics, vol. 7, no. 10, pp. 2601-2615, 2007.

[17] R. Fu, Y. Hu, J. S. Wright et al., "Short circuit of water vapor and polluted air to the global stratosphere by convective transport over the Tibetan Plateau," Proceedings of the National Academy of Sciences, vol. 103, no. 15, pp. 5664-5669, 2006.

[18] A. Gettelman, D. E. Kinnison, T. J. Dunkerton, and G. P. Brasseur, "Impact of monsoon circulations on the upper troposphere and lower stratosphere," Journal of Geophysical Research: Atmospheres, vol. 109, no. D22, 2004.

[19] X. L. Chen, Y. M. Ma, H. Kelder, Z. Su, and K. Yang, "On the behaviour of the tropopause folding events over the Tibetan plateau," Atmospheric Chemistry and Physics, vol. 11, no. 10, pp. 5113-5122, 2011.

[20] X. Chen, J. A. Añel, Z. Su et al., “The deep atmospheric boundary layer and its significance to the stratosphere and troposphere exchange over the Tibetan plateau," PLoS One, vol. 8, no. 2, Article ID e56909, 2013.

[21] M. van Peet, Z. Zhang, L. Su et al., "Resolving the impact of stratosphere-to-troposphere transport on the sulfur cycle and surface ozone over the Tibetan plateau using a cosmogenic 35 S tracer," Journal of Geophysical Research: Atmospheres, vol. 121, no. 1, pp. 439-456, 2016.

[22] X. Yin, S. Kang, B. de Foy et al., "Surface ozone at Nam Co in the inland Tibetan plateau: variation, synthesis comparison and regional representativeness," Atmospheric Chemistry and Physics, vol. 17, no. 18, pp. 11293-11311, 2017. 
[23] K. A. Browning and R. Reynolds, "Diagnostic study of a narrow cold-frontal rainband and severe winds associated with a stratospheric intrusion," Quarterly Journal of the Royal Meteorological Society, vol. 120, no. 516, pp. 235-257, 1994.

[24] A. J. Thorpe, "Attribution and its application to mesoscale structure associated with tropopause folds," Quarterly Journal of the Royal Meteorological Society, vol. 123, no. 544, pp. 2377-2399, 1997.

[25] M. Griffiths, A. J. Thorpe, and K. A. Browning, "Convective destabilization by a tropopause fold diagnosed using potential-vorticity inversion," Quarterly Journal of the Royal Meteorological Society, vol. 126, no. 562, pp. 125-144, 2000.

[26] M. A. Goering, W. A. Gallus, M. A. Olsen, and J. L. Stanford, "Role of stratospheric air in a severe weather event: analysis of potential vorticity and total ozone," Journal of Geophysical Research: Atmospheres, vol. 106, no. D11, pp. 11813-11823, 2001.

[27] L. W. Uccellini, "Processes contributing to the rapid development of extratropical cyclones," in Extratropical Cyclones: The Erik Palmén Memorial Volume, C. Newton and E. Holopainen, Eds., pp. 81-105, American Meteorological Society, Boston, MA, USA, 1990.

[28] H. Wernli, S. Dirren, M. A. Liniger, and M. Zillig, "Dynamical aspects of the life cycle of the winter storm 'Lothar' (24-26 December 1999)," Quarterly Journal of the Royal Meteorological Society, vol. 128, no. 580, pp. 405-429, 2002.

[29] M. Sprenger, M. Croci Maspoli, and H. Wernli, "A northern hemispheric climatology of cross-tropopause exchange for the ERA15 time period (1979-1993)," Journal of Geophysical Research, vol. 108, no. D12, p. D128518, 2003.

[30] M. Zhang, W. S. Tian, L. Chen, and D. Lü, "Cross-tropopause mass exchange associated with a tropopause fold event over the northeastern Tibetan Plateau," Advances in Atmospheric Sciences, vol. 27, no. 6, pp. 1344-1360, 2010.

[31] A. Ding and T. Wang, "Influence of stratosphere-to-troposphere exchange on the seasonal cycle of surface ozone at Mount Waliguan in western China," Geophysical Research Letters, vol. 33, no. 3, Article ID L03803, 2006.

[32] B. Škerlak, M. Sprenger, and H. Wernli, "A global climatology of stratosphere-troposphere exchange using the ERA-Interim data set from 1979 to 2011," Atmospheric Chemistry and Physics, vol. 14, no. 2, pp. 913-937, 2014.

[33] D. P. Dee, S. M. Uppala, A. J. Simmons et al., "The ERAInterim reanalysis: configuration and performance of the data assimilation system," Quarterly Journal of the Royal Meteorological Society, vol. 137, no. 656, pp. 553-597, 2011.

[34] E. Palmen and C. W. Newton, Atmospheric Circulation Systems: Their Structure and Physical Interpretation, Academic, New York, NY, USA, 1969.

[35] J. A. Añel, J. C. Antuña, L. de la Torre, J. M. Castanheira, and L. Gimeno, "Climatological features of global multiple tropopause events," ournal of Geophysical Research, vol. 113, Article ID D00B08, 2008.

[36] L. L. Pan, W. J. Randel, J. C. Gille et al., "Tropospheric intrusions associated with the secondary tropopause," Journal of Geophysical Research, vol. 114, no. D10, Article ID D10302, 2009.

[37] D. J. Seidel and W. J. Randel, "Variability and trends in the global tropopause estimated from radiosonde data," Journal of Geophysical Research, vol. 111, no. D21, Article ID D21101, 2006.

[38] T. Schmidt, G. Beyerle, S. Heise, J. Wickert, and M. Rothacher, "A climatology of multiple tropopauses derived from GPS radio occultations with CHAMP and SAC-C," Geophysical Research Letters, vol. 33, no. 4, Article ID L04808, 2006.

[39] W. J. Randel, F. Wu, and P. Forster, "The extratropical tropopause inversion layer: global observations with GPS data, and a radiative forcing mechanism," Journal of the Atmospheric Sciences, vol. 64, no. 12, pp. 4489-4496, 2007.

[40] R. J. Reed and E. F. Danielsen, "Fronts in the vicinity of the tropopause," Archiv für Meteorologie, Geophysik und Bioklimatologie Serie A, vol. 11, no. 1, pp. 1-17, 1958.

[41] B. J. Hoskins, M. E. McIntyre, and A. W. Robertson, "On the use and significance of isentropic potential vorticity maps," Quarterly Journal of the Royal Meteorological Society, vol. 111, no. 470, pp. 877-946, 1985.

[42] A. Kunz, P. Konopka, R. Müller, and L. L. Pan, "Dynamical tropopause based on isentropic potential vorticity gradients," Journal of Geophysical Research: Atmospheres, vol. 116, no. D24, 2011.

[43] E. V. Browell, E. F. Danielsen, S. Ismail, G. L. Gregory, and S. M. Beck, "Tropopause fold structure determined from airborn Lidar and in situ measurements," Journal of Geophysical Research, vol. 92, no. D2, pp. 2112-2120, 1987.

[44] M. A. Shapiro, "Turbulent mixing within tropopause folds as a mechanism for the exchange of chemical constituents between the stratosphere and troposphere," Journal of the Atmospheric Sciences, vol. 37, no. 5, pp. 994-1004, 1980.

[45] A. Ebel, H. Elbern, J. Hendricks, and R. Meyer, "Stratospheretroposphere exchange and its impact on the structure of the lower stratosphere," Journal of Geomagnetism and Geoelectricity, vol. 48, no. 1, pp. 135-144, 1996.

[46] H. Elbern, J. Hendricks, and A. Ebel, "A climatology of tropopause folds by global analyses," Theoretical and Applied Climatology, vol. 59, no. 3-4, pp. 181-200, 1998.

[47] E. Tyrlis, B. Škerlak, M. Sprenger, H. Wernli, G. Zittis, and J. Leliveld, "On the linkage between the Asian summer monsoon and tropopause fold activity over the eastern Mediterranean and the Middle East," Journal of Geophysical Research: Atmospheres, vol. 119, no. 6, pp. 3202-3221, 2014.

[48] B. Škerlak, M. Sprenger, S. Pfahl, E. Tyrlis, and H. Wernli, "Tropopause folds in ERA-Interim: global climatology and relation to extreme weather events," Journal of Geophysical Research: Atmospheres, vol. 120, no. 10, pp. 4860-4877, 2015.

[49] A. B. G. Bush and W. R. Peltier, "Tropopause folds and synoptic-scale baroclinic wave life cycles," Journal of the Atmospheric Sciences, vol. 51, no. 12, pp. 1581-1604, 1994.

[50] R. Rotunno, W. C. Skamarock, and C. Snyder, "An analysis of frontogenesis in numerical simulations of baroclinic waves," Journal of the Atmospheric Sciences, vol. 51, no. 23, pp. 3373-3398, 1994.

[51] P. James, A. Stohl, C. Forster, S. Eckhardt, P. Seibert, and A. Frank, "A 15-year climatology of stratosphere-troposphere exchange with a Lagrangian particle dispersion model: 2 . mean climate and seasonal variability," Journal of Geophysical Research, vol. 108, no. D12, p. 8522, 2003.

[52] P. Cristofanelli, A. Bracci, M. Sprenger et al., "Tropospheric ozone variations at the Nepal Climate Observatory-Pyramid (Himalayas, $5079 \mathrm{~m}$ a.s.l.) and influence of deep stratospheric intrusion events," Atmospheric Chemistry and Physics, vol. 10, no. 14, pp. 6537-6549, 2010. 

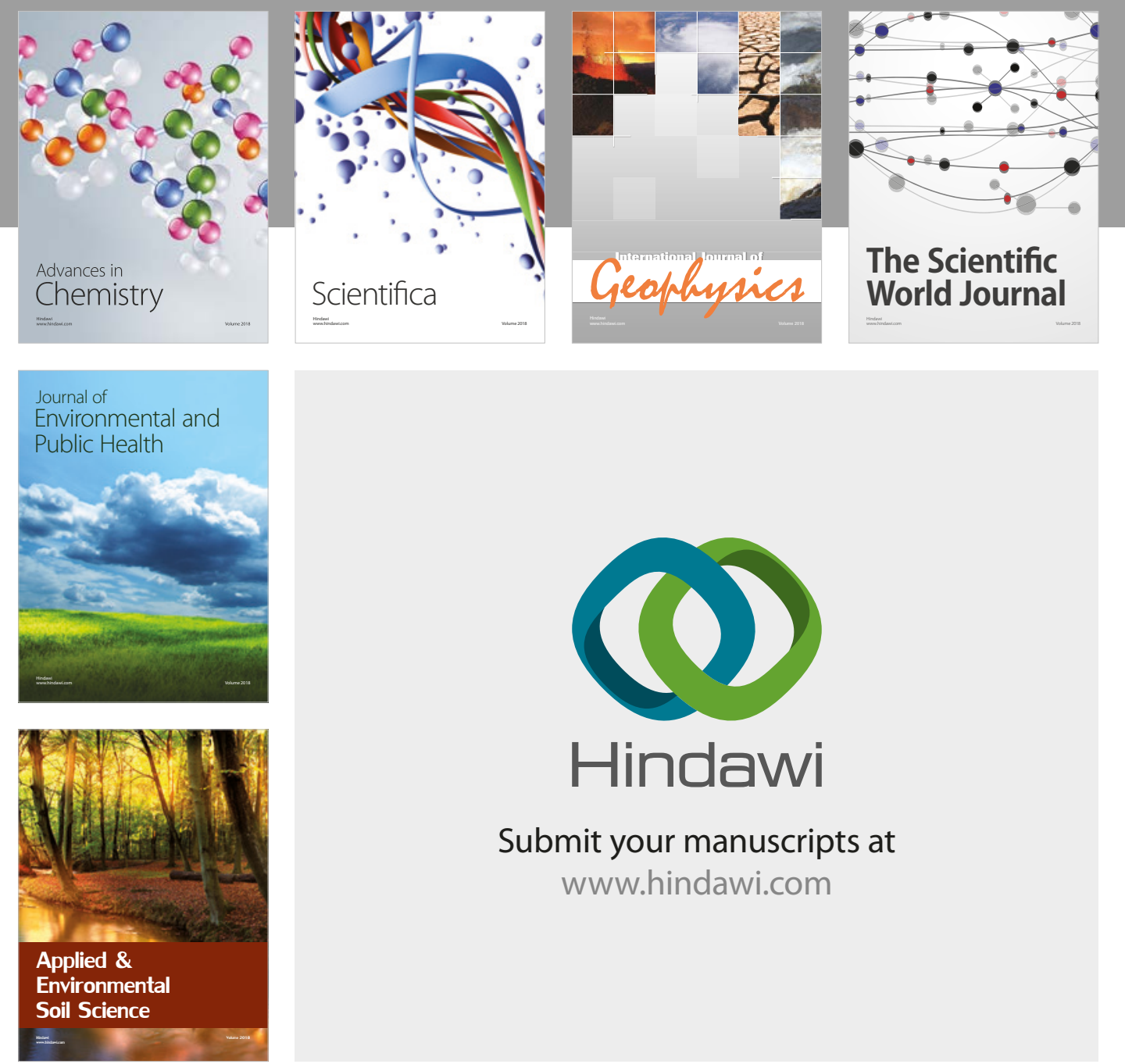

The Scientific

\section{World Journal}
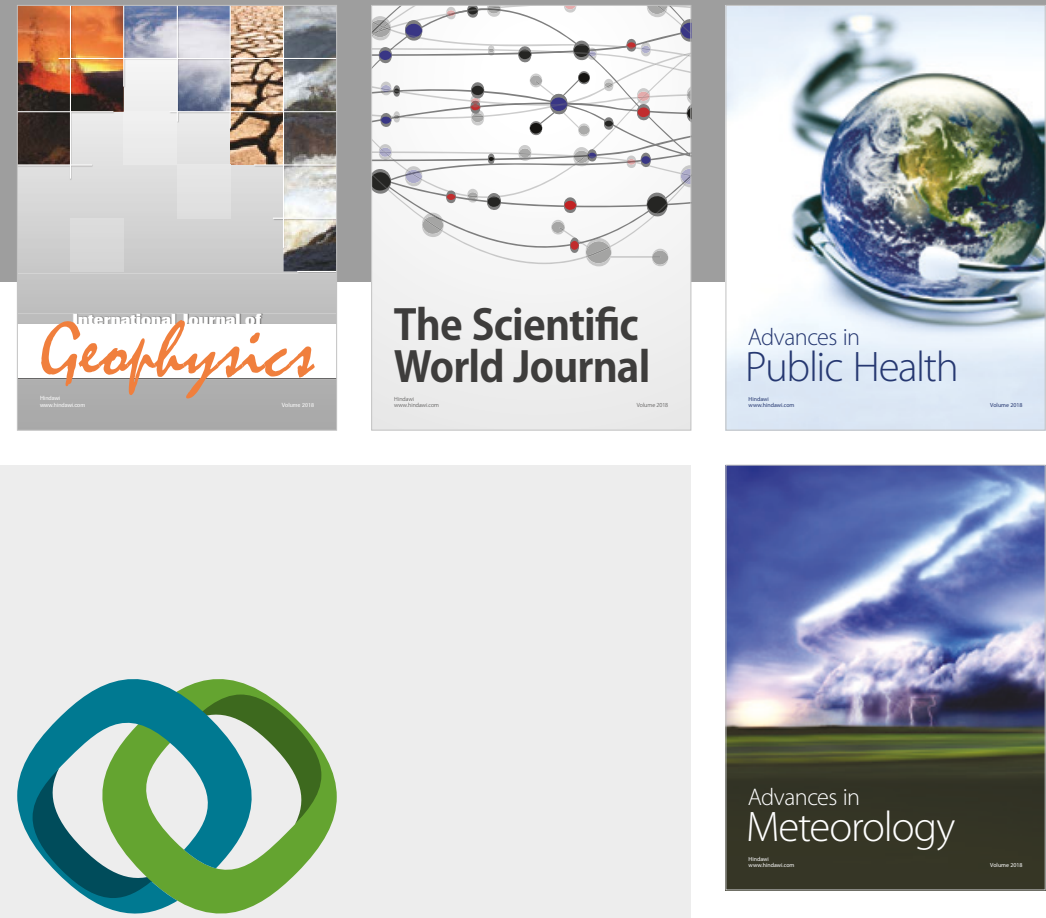

Advan

Public Health

\section{Hindawi}

Submit your manuscripts at

www.hindawi.com
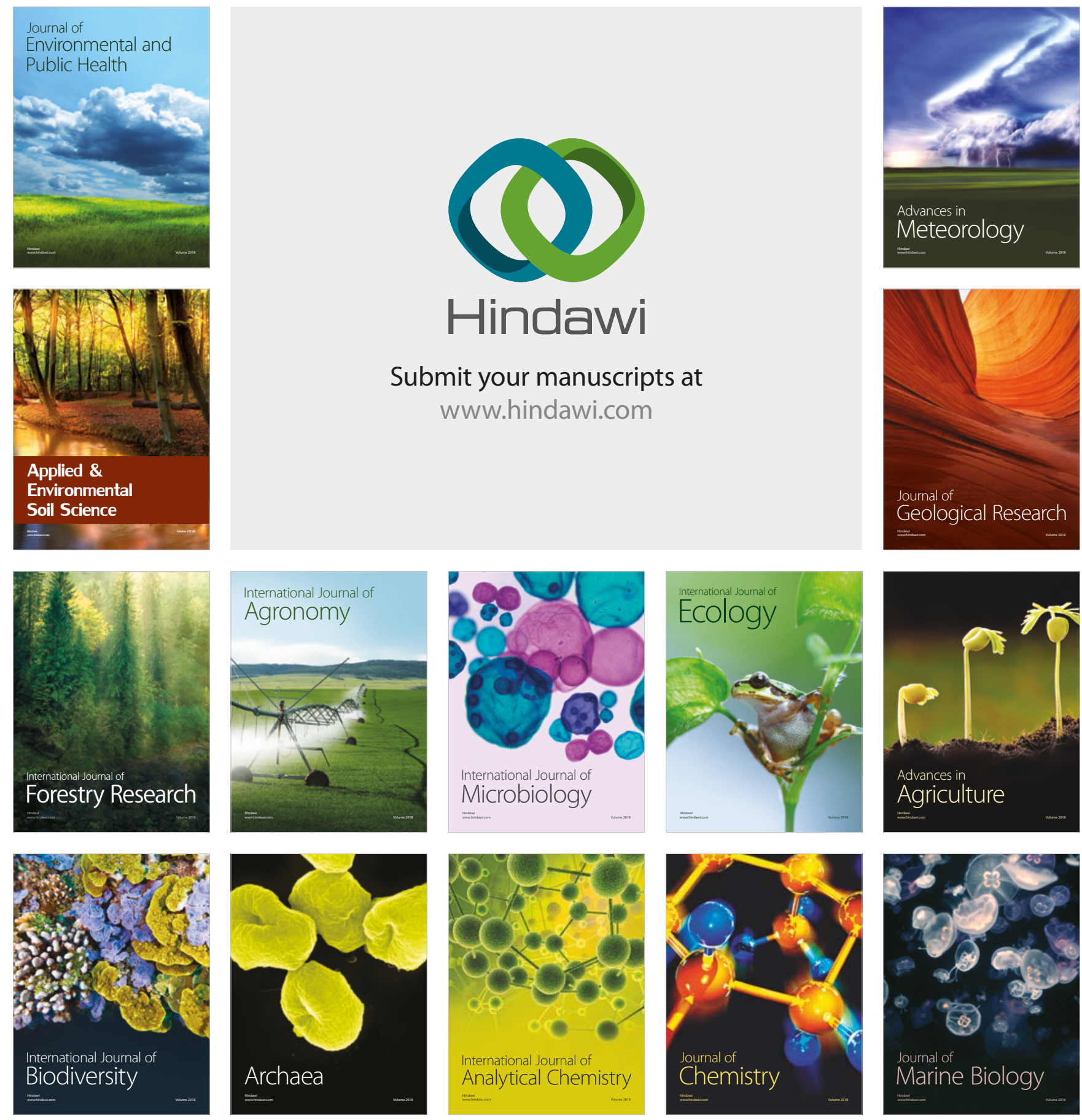